\title{
The Impact of IT Flexibility on Strategic Alignment (with Focus on Export)
}

\author{
Saeid Jorfi (Corresponding author) \\ Technological University of Malaysia (UTM) \\ DO6- Postgraduate Office (FPPSM)-Management Faculty \\ Skudi- Johor Baharu, Johor 81310, Malaysia \\ Tel: 60-176-121-137 E-mail: jsaeid2@live.utm.my \\ Khalil Md Nor \\ Technological University of Malaysia (UTM) \\ DO6- Postgraduate Office (FPPSM)-Management Faculty \\ Skudi- Johor Baharu, Johor 81310, Malaysia \\ Tel: 60-176-125-344 E-mail: kmdnor@fppsm.utm.my \\ Lotfi Najjar \\ University of Nebraska at Ohama \\ PKI 174-F. 1110 South 67 St. Omaha, NE 68182, USA \\ Tel: 1-402-554-2233 E-mail: lnajjar@unomaha.edu \\ Hassan Jorfi \\ Technological University of Malaysia (UTM) \\ DO6- Postgraduate Office (FPPSM)-Management Faculty \\ Skudi- Johor Baharu, Johor 81310, Malaysia \\ Tel: 60-176-125-344 E-mail: haassan_jorfee@yahoo.com
}

Received: September 6, $2010 \quad$ Accepted: January 13, $2011 \quad$ doi:10.5539/ijbm.v6n8p264

\begin{abstract}
Strategic alignment or the fit between information technology (IT) and business strategy remains a key topic of concern among managers worldwide. Change has always being considered the foremost challenge affecting strategic alignment. Planning for alignment in uncertain and dynamic environments is fraught with risk as organizations seek to understand how much flexibility to add to their IT infrastructure so as to maintain consistently high levels of alignment. Reviewing the literature showed that there is a positive relationship between IT infrastructure flexibility and strategic alignment with strategic information systems planning (SISP) serving as a moderator of this relationship. Additionally, according to literature on exporting area and logical arguments we proposed that export performance can moderators the link between IT flexibility and strategic alignment. Also, studies results emphasize the need for organizations to use SISP to consistently monitor the relationship between IT flexibility and alignment. Doing so during periods of increased change in dynamic and uncertain environments reduces the risk of being ensnared by rigidity traps that could transform IT into an inhibitor rather than an enabler of change.
\end{abstract}

Keywords: IT flexibility, Strategic alignment, Export performance, Strategic information systems planning 1. Introduction

As Grembergen and Haes (2008) truly observe, information technology and the use of it in business settings have undergone drastic changes in the past few decades. The late 1990's developments in information technology (IT) had created the most effective and comprehensive need for strategic change in business environments worldwide. By the same token, in the $21^{\text {st }}$ century, the majority of industrial, commercial and governmental bodies essentially have become reliant on their information technology. To put in Rockart's words, as indicated by Ward and Peppard (2002, p.1), "[i]nformation technology has become inextricably intertwined with business". 
In the case of successful IT management, the question of the IT's role in attaining the organizational strategic objectives arises. In an attempt to answer this question, Franz and Klepper (1995) claimed that generally adjustment to or alignment with the strategic goals of an organization epitomizes the proper role of IT in that institution.

Additionally, change is considered to be one of the fundamental challenges facing this strategic alignment (Luftman,Papp, and Brier, 1999). Characteristically, as it is stated by Mendelson and Pillai, (1998),incidents like price wars, reduced demand, the launch of new product by a rival, to name a few, motivate business strategy changes. However, different companies undergo different change processes. Take the example of the wood products industry, in which the change happens infrequently but incrementally. As Christensen (1997) puts it, in this industry life cycles of products are protracted and commoditized, at the same time, accompanied by few disruptive innovations. While in the banking industry, change is disruptive but frequent.

What has been discussed above indicates that information technology has increasingly grown in all industrial, commercial and governmental sectors. With the rapid growth of IT in all institutions, especially in commercial settings, the role of IT plays in attaining strategic goals has come forth as the crucial issue for the managers of business institutions. To put it differently, alignment of business and IT has gained importance for managers. Therefore, understanding effective factors in the alignment is of prime importance. The literature indicates, various factors have been identified, by academic researchers and business practitioners, as effective issues in the strategic alignment. In this research, the main factor that is considered to be the most influential in creating the strategic alignment is IT flexibility. Additionally, other factors such as strategic information systems planning (SISP) and export performance factors will be studied as effective factors on strategic alignment. By reviewing the existing literature, the researcher aims at identifying some relationships, and introducing the findings as the conceptual model.

\section{IT - Business Strategic Alignment}

The strategic alignment refers to the degree that business mission, objectives and plans support and, at the same time, are supported by information technology mission, objectives and plans (Reich and Benbasat, 1996, 2000).

In spite the emergence of an enormous number of new and embryonic technologies like World Wide Web services, utility, computing and radio frequency identification (RFID), executives still classify strategic alignment between IT and business strategy and consider it as the most crucial factor they confront in their companies (Luftman, Kempaiah, and Nash, 2006).

Strategic alignment is very vital and its importance was mentioned since the past decades, as Papp (1995) observes, the importance of strategic alignment has been substantiated since 1980's.

Review of the aforementioned studies reveals that the importance of the strategic alignment is due to its impact on a number of its principle business deeds, like gaining competitive advantage, competing in a tough competitive market, imposing positive effect in the performance of a company, highest return on IT investment, competing in a diverse market, supporting business strategies and contributing to business value achievement, resulting in better performance, introducing flexibility in response to new opportunities. All in all, the aforementioned issues suggest that strategic alignment is important due to the fact that organizations compete in a competitive turbulent market full of changes which needs IT to be flexible in order to adapt with predicted changes and unforeseen. Consequently, IT flexibility could be considered as a crucial competitive tool.

\section{Dynamic Environment}

In the era where change has become a life style, it becomes even more difficult for companies to foresee changes in their respective competitive contexts. In the newly emerging and unconventional contexts, customers have become competitors, and competitors partners. Businesses must go on despite potentially dramatically new business environments that are currently not well understood. IT investments, like others, need to continue in this uncertain environment (Loftman, 1996): How do organizations align IT investments with business in this climate.

Change has been considered by administrators as among the principal challenges in front of alignment (Luftman,Papp, and Brier, 1999). With companies revising their objectives in attaining efficiency or positioning in market, strategy as a set of performances -arranged as a value chain, shop, or network (Porter, 1985; Stabell and Fjeldstad, 1998) - might evolve or alter its course (Porter, 1996). Generally, events, such as price wars, reduce demand, and the launch of a new product to the market by a competitor, motivate business strategy alterations (Mendelson \& Pillai, 1998). The primary challenge with alignment, however, is whether IT can keep pace with the changes sought by firms, and, beyond this, how firms can better plan for, and architect, IT to respond to change. Not all firms experience change in the same way. Woods products industry, for instance, experiences infrequent and incremental changes. Products are commoditized and their life cycles are long, accompanying few disruptive innovations (Christensen, 1997).

In the case that organization are not only for preserving a sense of preparedness and agility but also attaining higher payoffs from IT, deciding on a strategy to deal with this sudden and unpredictable change is a crucial 
factor in Strategic Information Systems Planning (SISP) (Segars and Grover, 1999; Tallon, Kraemer, and Gurbaxani, 2000; Venkatraman and Ramanujam, 1987). IT might be considered as a source of sustainable profit only in the case that it changes quickly. If IT is slow to change - as is characteristic of legacy systems that lead to rigidity traps or organizational intransigence (Bharadwaj, 2000) - IT cannot be a source of sustainable advantage. On the other hand, if IT is responsive to change, firms are less likely to experience a decline in firm performance.

In the competitively flat and extremely unpredictable world (Friedman, 2006), the opportunity cost of misalignment has been increased, preserving alignment has also been rendered to much more complicated issue (Venkatraman, Henderson, and Oldach, 1993). Greater profitability (Chan et al., 1997), better market positioning (Kearns and Lederer, 2003), and superior IT business value (Tallon, Kraemer, and Gurbaxani, 2000) contribute in better recognition of alignment benefits. Nevertheless, firms are reluctant to implement IT resources which are, in short term proved to be beneficial and in the long term could trigger rigidity traps (Bharadwaj, 2000). In this case, changing the focus of IT and enabling it to support a revised strategy could be a complex task to perform for various reasons. Strategy considered as a dynamic response to environmental change, which is consistent with Porter's (1991) vision, dynamic alignment or a procedure to preserve a tough link between IT and business strategy even confronting with the sever market changes is the main objective of the firms (Sabherwal, Hirschheim, and Goles, 2001; Venkatraman, Henderson, and Oldach, 1993). Nevertheless, dynamic alignment achievement is indefinite.

The fact that, effective information Systems (IS) planning is due in part to qualifications like problem identification, environmental scanning, being able to react to change, and being able to use these capabilities for aligning IT with business strategy, (Earl, 1993; Segars and Grover, 1998) has been pinpointed in the literature. Implementation and the subsequent performance, according to Mintzberg and Waters (1985), are the determining factors in the effectiveness of any planning. Therefore, this study argues that utilizing IT infrastructure flexibility could be effective in producing tighter fit between IT and business strategy in the unpredictable and turbulent modern market.

\section{Export Performance and Dynamic Environments}

A new venture to internationalize its sales can be forced by environmental dynamism and the ensuing turbulence (Oviatt \& McDougall, 1994). Erramilli \& D'Souza (1993) and Root (1994) stated exporting does not require large investments, so can be attractive to new ventures. This is an important aspect since environmental turbulence typically reduces organizational slack as stated by Slater \& Narver (1994), which can limit the venture's ability to pursue more expensive international choices such as foreign direct investment. It is important to note that exporting can provide new market opportunities for firms and reduces their reliance on a changing, volatile domestic environment. Thus, the venture can "hedge its bets"; exporting is similar to holding a portfolio of stocks because it reduces the influence of major fluctuations in the domestic market on new venture performance, Exporting can also assist the venture achieve stability through market diversification (Barker \& Kaynak, 1992). As a result, the researchers believe that there is a significant positive relationship between the perceived dynamism of a new venture's domestic market and export performance. The firms will attempt to manage dynamism in its domestic market and decrease the sources of turbulence by going global market (Hitt, Hoskisson \& Ireland, 1994) and becoming an active exporter.

\section{IT Flexibility}

Flexibility is regarded as the degree of leveraging processes and procedures, by managers, in controlling their respective operative contexts (Byrd \& Turner, 2000).

Pervious researches of Davenport and Linder (1994), Keen (1991), Tallon (2007), Weill and Broadbent (1998), among others, recognize the importance of applying an IT infrastructure which is flexible, in supporting shared services, best-of-breed applications, as well as inter- and intra-organizational connectivity that could be scaled to accommodate growth in the user base. More than half of the total IT budgets are consumed by IT infrastructure (Gurbaxani, Melville, and Kraemer, 1998; Weill and Broadbent, 1998). It is claimed that the major share of this IT budget provides little business value to companies (Carr, 2003). On the contrary, resource-based theorists argue that the expenditure of value generating capacities is high rather than that of IT (Bharadwaj, 2000; Ray, Muhanna, and Barney, 2005; Sambamurthy, Bharad waj, and Grover, 2003). Similarly, the previous studies accentuate the qualities which enable IT infrastructure to scale with regard to requirements of the end-user or to vary in scope in a way that infrastructure can accommodate an eclectic mix of IT applications, operating systems, and data formats (Duncan, 1995; Keen, 1991). In addition, Weill, Subramani, and Broadbent (2002) consider a flexible IT infrastructure as a fundamental element in organizations' attempt to improve strategic ability.

In the case that the organization's IT is inflexible, the ability of IT infrastructure as an enabler might immensely be reduced. Being familiar with the elements that contribute in having a flexible IT infrastructure is crucial in avoiding implementing an inflexible IT infrastructure.

Duncan (1995) and Byrd and Turner's (2000) explorations conceptualize the flexibility of IT infrastructure in terms of four constructs: hardware compatibility, software modularity, network connectivity, and IT skills 
adaptability. These four constructs define IT infrastructure, autonomously and collectively, as the IT infrastructure ability in scaling and evolving easily, quickly and in accordance with the requirements of the market. Therefore, in the case that hardware is incompatible, networks cannot scale, software cannot be easily customized or changed, and skills are proprietary or linked to a specific technology platform and, with little relevance elsewhere, rigidity traps occur. Implementing these constructs, Tallon (2007) discovered that the flexibility of an IT infrastructure is either an important predicator of agility or a factor which renders the organizational revision process of configuration in an easy and fast procedure. It might also be the output of fundamental business processes. In the same vein, Ross, Weill, and Robertson (2006) utilized architecture maturity as a predicator of adaption process and operational success. The most prominent outcome of their study is the discovery that as infrastructure matures, through substituting either local or process-level flexibility for global of firm-wide flexibility, IT matures as well.

\section{Strategic Information Systems Planning}

Hartono et al. (2003) define strategic information systems planning (SISP) as "the process of identifying a portfolio of computer-based applications that will assist an organization in executing its business plans and realizing its business goals". Particularly, the aims of SISP are: (1) establishing symbiosis between information systems and business objectives; (2) outperforming rivals; (3) managing information resources effectively; and (4) developing an information technology (IT) infrastructure and a portfolio of prioritized applications consistent with the information vision of the organization. Therefore, it is not startling that the majority of scholars consistently rank this issue among the top ten issues in almost all IT researches of organizations in the past two decades or so (Brancheau, Janz, and Wetherbe, 1996; Brown, 2004)

As an example in point, the results of the survey conducted in December 2004 in the United States reveal that, out of the top ten prominent factors firms confront, strategic planning for IT emerged as the fourth issue (Maltz and DeBlois, 2005). Likewise, other scholars, such as Segars and Grover (1999) have emphasized the importance of planning, observing that "Improving strategic planning within the realm of information technology management is consistently identified by top corporate executives as a critical competitive issue".

Previous research indicate that information systems (IS) planning success is the result of capabilities such as problem identification, environmental scanning, and ability to embrace change, and an ability to use these capabilities for aligning IT with business strategy (Earl, 1993; Segars and Grover, 1998).

As it is mentioned before, the literate on IT flexibility indicate that organizations with flexible IT infrastructure might sustain tight link between IT business strategy, since they are better able to support a change in business strategy. IS planning might contribute in maintaining the relationship through creating a platform for firms to scrutinize environmental or market factors which might result in a change in the business strategy. It might be claimed that SISP is a process that draws upon skills like knowing how to use IT to respond to market threats and opportunities. Drawing upon these arguments, it could reasonably be stated the SISP moderates the fit between IT infrastructure flexibility and strategic alignment, in positive manner.

\section{Conceptual Framework}

The model for this paper is composed of four key constructs (see Figure1) including IT flexibility, strategic alignment, information system strategic planning, and export performance. Based on existing literature-as stated earlier- there is the positive relationship between IT infrastructure flexibility and strategic alignment with strategic information systems planning (SISP) serving as a moderator of this relationship. Also, reviewing the literature showed that exporting can help the venture achieve stability through market diversification. In other word, exporting influence dynamic conditions of organizations through market diversification. As noted earlier, dynamic environments can impact IT flexibility with regard to strategic alignment. Therefore, we can propose that export performance moderators the link between IT flexibility and strategic alignment.

From the model, the following proposition is derived.

- P1: IT flexibility will have a significant relationship with strategic alignment.

- P1a: Modularity will have a significant relationship with strategic alignment.

- P1b: Compatibility will have a significant relationship with strategic alignment.

- P1c: Connectivity will have a significant relationship with strategic alignment.

- P1d: Manager's skills will have a significant relationship with strategic alignment.

- P2: SISP moderates the relationship between IT flexibility and strategic alignment.

- P3: Export performance moderates the relationship between IT flexibility and strategic alignment.

\section{Discussion}

The strategic alignment refers to the degree that business mission, objectives and plans support and, at the same time, are supported by information technology mission, objectives and plans. Change has been considered by administrators as among the principal challenges in front of alignment. However, different companies undergo different change processes. The primary challenge with alignment, however, is whether IT can keep pace with 
the changes sought by firms, and, beyond this, how firms can better plan for, and architect, IT to respond to change. IT might be considered as a source of sustainable profit only in the case that it changes quickly. If IT is slow to change - as is characteristic of legacy systems that lead to rigidity traps or organizational intransigence-IT cannot be a source of sustainable advantage. On the other hand, if IT is responsive to change, firms are less likely to experience a decline in firm performance. Reviewing the literature showed that there is a positive relationship between IT infrastructure flexibility and strategic alignment with strategic information systems planning (SISP) serving as a moderator of this relationship.The fact that, effective information Systems (IS) planning is due in part to qualifications like problem identification, environmental scanning, being able to react to change, and being able to use these capabilities for aligning IT with business strategy has been pinpointed in the literature. Therefore, this study argues that utilizing IT infrastructure flexibility could be effective in producing tighter fit between IT and business strategy in the unpredictable and turbulent modern market. It is worthy to note that exporting can provide new market opportunities for firms and reduces their reliance on a changing, volatile domestic environment. Thus, the venture can "hedge its bets"; exporting is similar to holding a portfolio of stocks because it reduces the influence of major fluctuations in the domestic market on new venture performance, Exporting can also assist the venture achieve stability through market diversification (Barker \& Kaynak, 1992). As stated earlier, it is argued that there is a significant positive relationship between the perceived dynamism of a new venture's domestic market and export performance. Thus, firms will attempt to manage dynamism in its domestic market and decrease the sources of turbulence by going global market (Hitt, Hoskisson \& Ireland, 1994) and becoming an active exporter.

\section{Limitations}

The present research is concerned with the study of IT flexibility and its impact on strategic alignment. As such, there are many areas for strategic alignment and for further research. In particular, the researcher has found that the study is subject to some important limitations. The first and most important limitation of this study is limited by existing literature. A second limitation concerns the proposals made by this study may require policy decisions and top management support for implementations.

\section{Recommendations}

IT flexibility, as an important issue of organizations needs a lot of research in the developing countries like Iran. There is also need to carry out research regarding intrinsic and extrinsic factors which have impact on IT flexibility. Sector wise research may also be carried out to see the IT flexibility level in different sectors of countries. On the other hand, further studies with respect to impact of IT flexibility on strategic alignment by different organizations, are required in this field especially in the Iran whether it's manufacturing industry or service industry. It is important to note that studying, the relationship between IT flexibility and strategic alignment needs empirical researches in the different organizations.

\section{References}

Avison, D. et al. (2002). Using and Validating the Strategic Alignment Model. Journal of Information Systems, Vol. 13, pp. 223-246.

Barker, A. T., \& Kaynak, E. (1992). An empirical investigation of the differences between initiating and continuing exporters. European Journal of Marketing, Vol 26(3), 27-36.

Bharadwaj, A. (2000). A resource-based perspective on information technology capability and firm performance: an empirical investigation. MIS Quarterly, Vol. 24, 1, 169-196.

Brown, I.T.J. (2004). Testing and extending theory in strategic information systems planning through literature analysis. Information Resources Management Journal, Vol. 17, 4, $20-48$.

Byrd, T.A., and Turner, D.E. (2000). Measuring the flexibility of information technology infrastructure: exploratory analysis of a construct. Journal of Management Information Systems, Vol. 17, 1, 167-208.

Carr, N. (2003). IT doesn't matter. Harvard Business Review, Vol. 81, 5, 41-49.

Chan, Y.E., Huff, S.L., Barclay, D.W., and Copeland, D.G. (1997). Business strategy orientation, information systems orientation and strategic alignment. Information Systems Research, Vol. 8, 2, 125-150.

Christensen, C.M. (1994). The Innovator's Dilemma. Cambridge. MA: Harvard Business School Press.

Davenport, T., and Linder, J. (1994). Information management infrastructure: the new competitive weapon. Proceedings of the Twenty-seventh Annual Hawaii International Conference on Systems Sciences. IEEE, pp. 885-899.

De Haes S., \& Van Grembergen W. (2008). Practices in IT governance and business/IT alignment, Information Systems Control Journal, Vol. 2.

Duncan, N. (1995). Capturing flexibility of information technology infrastructure: a study of resource characteristics and their measure. Journal of Management Information Systems, Vol. 12, 2, 37-57.

Earl, M.J. (1993). Experiences in strategic information systems planning. MIS Quarterly, Vol. 17, 1, 1-24. 
Erramilli, M. K., \& D'Souza, D. E. (1993). Venturing into foreign markets: The case of the small service firm. Entrepreneurship Theory \& Practice, Vol. 17(4), 29-41.

Franz, C.R., and R. Klepper. (1995). Information Technology and Business Strategy in Romania. International Journal of Information Management, Vol. 15, 451-461.

Friedman, T.L. (2006). The World Is Flat. New York: Farrar, Straus, and Giroux.

Gurbaxani, V., Melville, N., and Kraemer, K.L. (1998). Disaggregating the return on investment to IT capital. In J.I. DeGross, R. Hirschheim, and M. Newman (eds.), Proceedings of the Nineteenth International Conference on Information Systems. Helsinki, Finland: Association for Information Systems, Atlanta, GA, pp. 376-380.

Hartono, E, Lederer, A.L, Sethi, V., and Zhuang, Y. (2003). Key predictors of the implementation of strategic information systems. DATA BASE for Advances in Information Systems, Vol. 34, 3, 41-53.

Hitt, M. A., Hoskisson, R. E., \& Ireland, R. D. (1994). A mid-range theory of the interactive effects of international and product diversification on innovation and performance. Journal of Management, Vol. 20(2), 297-326.

Kearns, G.S., and Lederer, A. (2003). A resource-based view of strategic it alignment: how knowledge sharing creates competitive advantage. Decision Sciences, Vol. 34, 1, 1-29.

Keen, P. (1991). Shaping the Future: Business Design Through Information Technology. Boston: Harvard Business School Press.

Luftman, J.N. (1996). Competing in the information age: strategic alignment in practice. Oxford University Press, New York; Oxford. Press.

Luftman, J.N., Kempaiah, R., and Nash, E. (2006). Key issues for IT executives 2005. MIS Quarterly Executive, Vol. 5, 2, 27-45.

Luftman, J.N., Papp, R., and Brier, T. (1999). Enablers and inhibitors of business-IT alignment. Communications of the AIS, Vol. 1, 11, 1-32.

Maltz, L., and DeBlois, P.B. (2005). Top ten IT issues 2005. Educause Review, Vol. 40, 3, 14.

Mendelson, H., and Pillai, R.R. (1998). Clockspeed and informational response: evidence from the information technology industry. Information Systems Research, Vol. 9, 4, 415-433.

Mintzberg, H., and Waters, J.A. (1985). Of strategies, deliberate and emergent. Strategic Management Journal, Vol. 6, 3, 257-272.

Oviatt, B. M., \& McDougall, P.P. (1994). Toward a theory of international new ventures. Journal of International Business, Vol. 25(1), 45-64.

Papp, R. (1995). Determinants of Strategically Aligned Organizations: A Multiindustry, Multi-perspective Analysis, (Dissertation), Hoboken, NJ: Stevens Institute of Technology.

Porter, M.E. (1980). Competitive Strategy: Techniques for Analyzing Industries and Competitors. New York: Free Press.

(1985). Competitive Advantage. New York: Free Press.

1991.

(1996). Towards a dynamic theory of strategy. Strategic Management Journal, 12 (Winter), Vol. 95-117,

What is strategy? Harvard Business Review, Vol. 74, 6, 61-77.

CRITO, University of California, Irvine.

Reich, B. H., and Benbasat, I. (1996). Measuring the linkage between business and information technology objectives. MIS Quarterly, (20:1), pp 55-78.

Ross, J.W., Weill, P., and Robertson, D.C. (2006). Enterprise Architecture as Strategy. Cambridge, MA: Harvard Business School Press.

Sabherwal, R., Hirschheim, R., and Goles, T. (2001). The dynamics of alignment: insights from a punctuated equilibrium model. Organization Science, Vol. 12, 2, 179-197.

Segars A.H., and Grover, V. (1999). Profiles of strategic information systems planning. Information Systems Research, Vol. 10, 3, 199-232.

Segars, A.H., and Grover, V. (1999). Profiles of strategic information systems planning. Information Systems Research, Vol. 10, 3,199-232.

Slater, S. F., \& Narver, J. C. (1994). Does competitive environment moderate the market orientation-performance relationship? Journal of Marketing, Vol. 58(1), 46-55.

Tallon, P.P. (2007). Inside the adaptive enterprise: an information technology capabilities perspective on business.

Tallon, P.P., Kraemer, K.L., and Gurbaxani, V. (2000). Executives' perceptions of the business value of 
information technology: a process-oriented approach. Journal of Management Information Systems, Vol. 16, 4, $145-173$.

Venkatraman, N., Henderson, J.C., and Oldach, S.H. (1993). Continuous strategic alignment: exploiting IT capabilities for competitive success. European Management Journal, Vol. 11, 2, 139-149.

Ward, J., \& Peppard, J. (2002). Strategic Planning for Information Systems. John Wiley \& Sons: Chichester.

Weill, P., and Broadbent, M. (1998). Leveraging the New Infrastructure: How Market Leaders Capitalize on Information Technology. Cambridge, MA: Harvard Business School Press.

Weill, P., Subramani, M., and Broadbent, M. (2002). Building IT infrastructure for strategic agility. Sloan Management Review, Vol. 44, 1, 57-65.

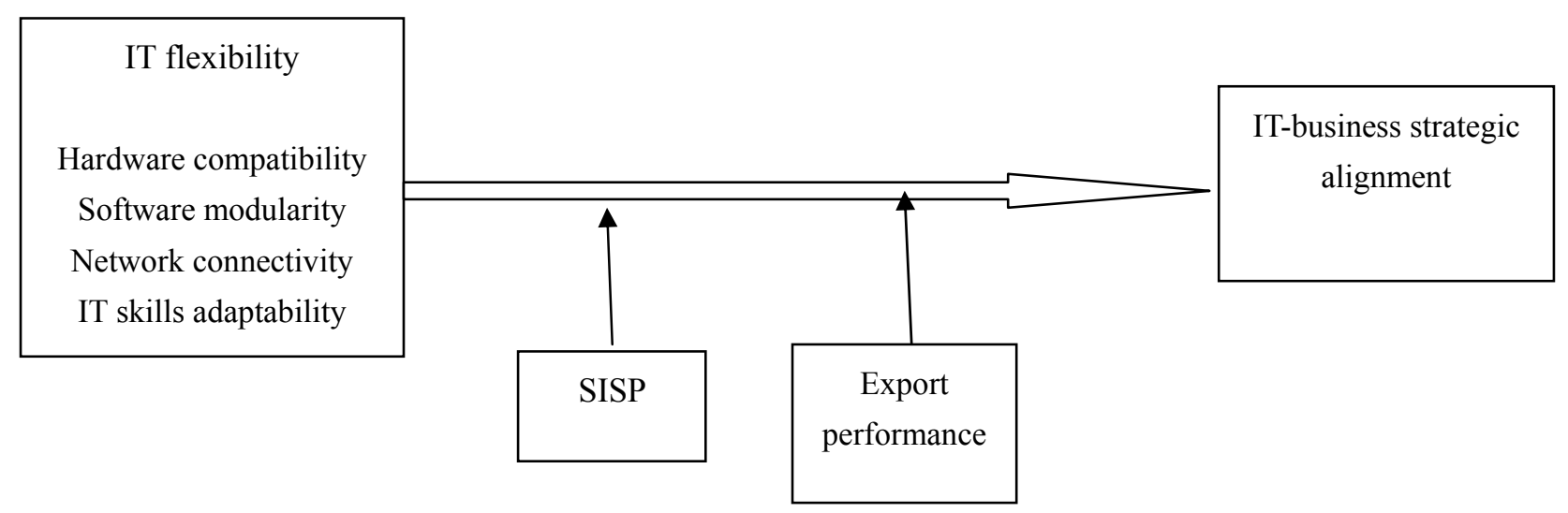

Figure 1. Conceptual Framework 